\title{
Research on the Formation Mechanism and Elements of the Financial Industrial Cluster
}

\author{
Lixia Yu*, Huifang Liu, Jingping Qiu \\ School of Business, Sichuan Normal University, Chengdu, China \\ Email: *yulixia@sicnu.edu.cn
}

Received 13 October 2015; accepted 26 October 2015; published 29 October 2015

Copyright (C) 2015 by authors and Scientific Research Publishing Inc.

This work is licensed under the Creative Commons Attribution International License (CC BY). http://creativecommons.org/licenses/by/4.0/

c) (i) Open Access

\begin{abstract}
Based on Patrick's Demand-Following and Supply-Leading financial system theory, the paper summarizes and compares the two kinds of formation mechanism of the financial industrial cluster in detail: the market-led model and the government-led model. And further, it summarizes six basic elements of the financial industry cluster needs to have, so as to point out the direction of China's major urban construction and development of the financial industry cluster, especially cities must take full advantage of government's support for the financial industry development and make the supply-Leading under the government-led model as the main formation mechanism.
\end{abstract}

\section{Keywords}

Financial Industrial Cluster, The Market-Led Model, The Government-Led Model, Demand-Following, Supply-Leading

\section{Introduction}

In the accelerating process of globalization, a striking phenomenon is that production globalization fails to make the production and business activities of enterprises to be balanced in the spatial distribution, but make the geographic clustering phenomenon of the related production activities become more and more obvious. In the process of industrialization, a new form of business organization was created, industry clusters, which was becoming an important driving force of economic development both in developed and developing countries. Industry cluster is a space aggregation with unique compition advance formed by a number of enterprises within a farm-out and criss-cross net of enterprises ship, which is a new and efficient modern industry form of organization between market and bureaucracy [1].

${ }^{*}$ Corresponding author.

How to cite this paper: Yu, L.X., Liu, H.F. and Qiu, J.P. (2015) Research on the Formation Mechanism and Elements of the Financial Industrial Cluster. Journal of Service Science and Management, 8, 773-780.

http://dx.doi.org/10.4236/jssm.2015.85078 
From the 1970s, the industry cluster is gradually applied to the core of modern economy-finance. From the initial few banks to the rise of financial holding company, and until today the spatial agglomeration and business outsourcing of various financial institutions, the financial industry cluster has become a phenomenon that cannot be ignored. In a time of highly developed IT, the financial industry cluster like "a sticky points" on a smooth space attracts a lot of economic energy. Through the agglomeration effects, the scale effects, the information spillover effects, and the innovative effects, etc., it promotes the area's economic development and becomes the backbone of the improving modern regional economic competitiveness. Therefore, the financial industry cluster is not only a focus issue of financial research, but also a new bright spot of the industry cluster research. Through the analysis of the typical financial industry cluster formation path, we can see that the formation of cluster is not a spontaneous phenomenon but also is completed by all the favorable factors. It is very meaningful to study the formation of financial industry cluster, cities can set up the financial industry cluster so as to better support the development of regional economy.

\section{Literature Review}

The connotation of financial industry cluster is very rich, different scholars defined it from different angles. Wangbu Fang (2006) believes that the financial industry cluster refers to a variety of enterprise and organizations based on portrait specialization and horizontal competition collaborating partnership, a large gathering in a specific area of the economy and the formation of aggregates industry organizations. Financial industry cluster combines the functions of the financial markets and the financial enterprise government-led, it can be formed a stable, sustained and orderly financial ecological organizations, which have overall competitive advantage that financial markets and other financial organizations that are not owned, for example the capable of financial integration, competitiveness, attraction and influence [2]; Lian Jianhui, Sun huanMin, Zhong huiBo (2006) argue that the financial industry cluster is a microscopic basis of the formed financial center and a middle network organization of production and trading of compounded financial products, and it has three advantages that regional financial innovation, financial risk mitigation and improving production and operation efficiency of financial institutions [1]; Teng Chunjiang (2006) believes that the financial industry cluster is financial institutions and related supported enterprise and middle network organization that have geographic proximity, trade proximity, social proximity gathered in an area and reach a certain size and intensity, thus better coordination of financial resources [3]; Liang Ying (2006) believes that the financial industry cluster is financial institutions that have headquarters function centralized to a specific geographical area, for instance a country's financial regulators, financial intermediaries, multinational financial companies and domestic financial companies, and particular industry space structure that there is a close link between with other international (multinational) institutions, multinational corporations, domestic large corporate headquarters [4].

Integrated view of the above scholars, we believe that the complete definition of the financial industry cluster needs from both dynamic and static perspective: dynamic financial industry cluster is a organic process, it emphasized that the financial resources gather to the certain space regions that have certain natural, economic and social advantages under certain conditions, formed financial market and financial institutions that have certain size and concentration [5]; But the static financial industry cluster is a state, is a financial industry organizations form after the various financial elements concentrated in a certain area, which is different from the financial markets, either from the middle network organization of financial enterprises. Differenr from traditional financial enterprise organizations model that emphasized to find and nurture competitiveness from the design of organization structure and individual internal, financial industry cluster emphasized to enhance the competitiveness of enterprises by compete, promote, cooperation and complementary under the conditions that of specialization.

For the elements of the formation of financial industry cluster, domestic and foreign scholars put forward their views from information sharing, transaction costs, economies of scale point. Friedman (1986) believes that the financial industry clusters mostly concentrated in the central business district of the city in order to obtain the advantages such as information, transportation, communications, human capital, etc. [6]. Davis (1988) aims to "business location theory" applied to the formation factors of financial industry cluster. After he investigated the situation of financial institutions site, he found that "profit maximization" was the criteria of the financial institution siting, therefore the site of financial institutions and the financial industry together to form clusters will consider three main factors: whether the region can offer production factors such as entrepreneurship and business environment that it is necessary for their normal operation, the regional scale and critical level of demand 
for financial services, the level of development and innovation of financial industry in the region; Taylor (Taylor, Petal, 2003) conducted empirical study on financial industry clusters in London, and the results showed that the gathering of skilled financial professionals is one of the most important driving force of London financial industry cluster formation; Chinese scholars Fan fangzhi (2004) conducted empirical research on domestic and foreign banks gathered in Shanghai, and research shows that the main drivers of Shanghai financial industry cluster formation due to the market factors oriented to economic interests and the government policies [7]; Hu Jian (2003) believes that economic factors, financial and political factors can affect the formation of financial industry cluster, in general, the region with the good economic basis, the developed of financial, the stable of political status easily form the financial industry cluster [8]; Liang Ying (2006) summarizes the influence factors of financial aggregated as four aspects: the geographic location of the region (including the time zone, transportation and business costs, etc.), the supply and demand of regional market, the historical factors of the region and the promote force of local government and so on [4].

\section{The Formation Mechanism of Financial Industry Cluster}

In the 1960s and 1970s, the Western development economist Patrick (1966) proposed the Demand-Following and Supply-Leading financial system theory [9], which revealed the relationship between the economic development and the expansion of the financial system. Patrick believed that the financial system of a region or country can be produced by two paths: one was Demand-Following, and another was Supply-Leading. The Demand-Following theory holds that: with the economic growth, all the economic sectors of society inevitably increase the demand for the financial services, which will lead to further expansion of the financial system. The emergence and development of the financial system is an automatic reaction to the economy growth. According to the Supply-Leading theory, with the development of the financial industry, the savings will increase and will be transformed into investment through the various financial institutions, which improves the efficient allocation of funds and greatly promotes the economic growth through the multiplier effect. The financial industry is a necessary condition for the economic development and supports the development of real economy, therefore the government often intends to support the expansion of the financial system. Corresponding to the DemandFollowing theory and the Supply-Leading theory, the formation mechanism of financial industry cluster can be summarized to two paths, are the market-led model and the government-led model.

\subsection{Demand-Following: The Market-Led Financial Industry Cluster}

The market-led model (also known as the natural evolution type) is a path adapted to the Demand-Following theory, and it considers the formation and development of the financial industry cluster as the inevitable requirement of production exchange and economic development. Due to the development and growth of the real economy, there is a growing demand for the financial services. Because of this demand, the financial institutions have changed and formed the cluster in one place. It can promote the innovation of financial instruments, the well-development of financial markets, the abundance of financial information, and the soundness of financial laws and regulations, ultimately it can prompt the formation of financial industry cluster in the region (see Figure 1). Such financial industry cluster model is a natural formation pattern, and some elements like contingency,

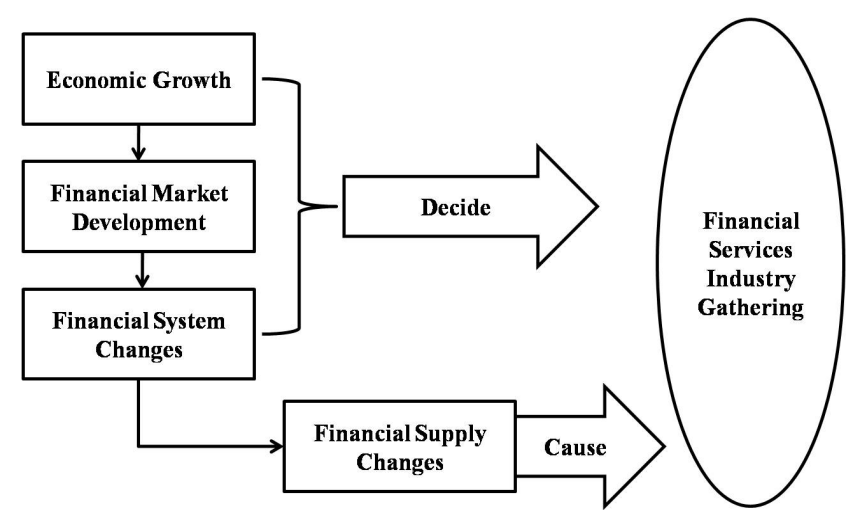

Figure 1. The process of market-led financial industry cluster [11]. 
a history or special events are often plays a decisive role in the process of formation. Once the initial regional advantages have been formed, the financial industry cluster would form a correlation effect through the financial industry to consolidate the effect of financial industry cluster and enhance the stability and scale of the cluster [10]. Therefore the financial industry cluster is not formed overnight, and it experiences the process of gathering from a single financial institution, to the services associated with financial institutions, and finally to the mature and stable financial industry cluster. It must go through a few decades even centuries of evolution. London financial industry cluster is a typical representative formed by this mechanism.

The market-led financial industry cluster generally relies on strong national economic power. The countries' economic and trade has a high development, it will attract a lot of foreign enterprises to invest and set up the branches in these countries, and the liquidity capital will gather here. Thus, the financial markets, the financial services, and the financial institutions will be rapidly expanded, which finally formed a cluster. The corresponding financial centers of the financial industry cluster generally have a predominant location, perfect urban infrastructure (including transport, communications, etc), excellent financial professionals and other hardware and software support. Once these advantages have been formed, the stability of the cluster is bound to further be consolidated, and the attractiveness of the city and radiation effects on the surrounding area will be enhanced. At the same time, the city and country with the financial industry cluster should have an open financial market and loose policy, which is the only way to stimulate the financial innovation, to create a mature financial market and to attract the global multinational financial institutions. The competition brings increased efficiency, then the financial industry can form a virtuous circle, which brings a long-term prosperity of the financial market.

\subsection{Supply-Leading: The Government-Led Financial Industry Cluster}

The government-led model is adapted to the Supply-Leading theory, which holds that in the formation process of the financial industry cluster, the state or local government would launch a space layout according to the economic development strategy. And in accordance with the relevant standards to evaluate the economic and financial situation of the city, and then select a city with sound financial foundation and development potential for the financial industry cluster. While giving quite loose and flexible industrial policy to support and guide the location of financial institutions and the direction of financial capital investment, to drive the rapid development of the financial markets and form the financial industry cluster (see Figure 2). Singapore financial industry cluster

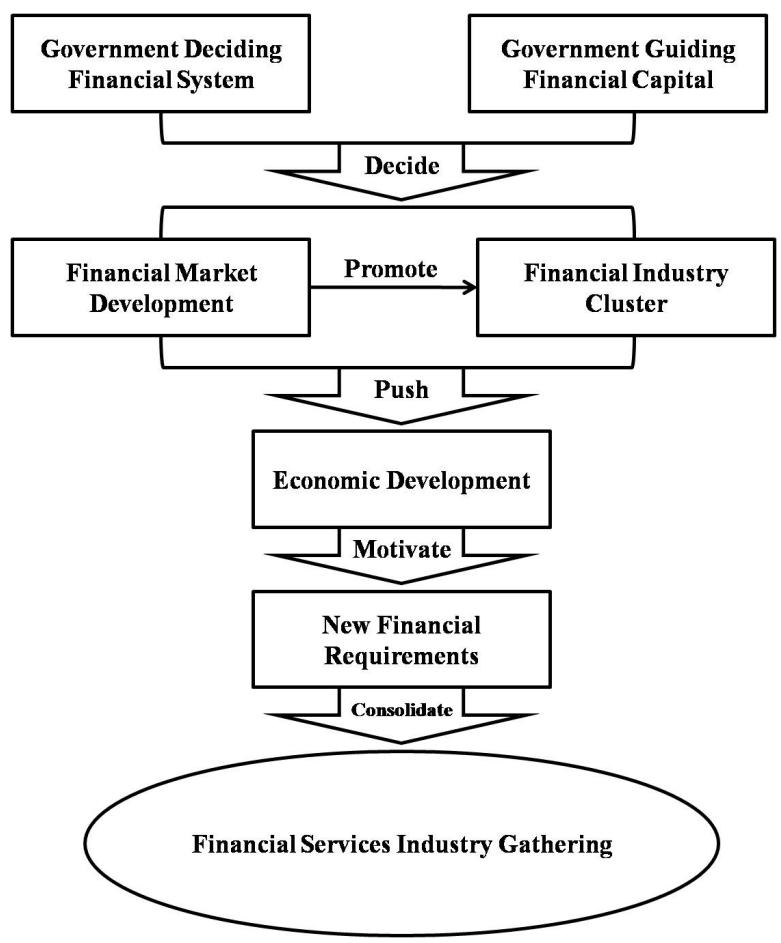

Figure 2. The process of the government-led financial industry cluster [11]. 
is a successful case formed by the government-led model.

Government-led financial industry cluster is mostly generated in the emerging industrial countries (or regions) after the World War II. The main reason is that the trend of the global economy integration becomes more and more evident after the World War II, and the industrial gradient shifts in the global scope, and the financial capital flows around the world. Compared to the developed capitalist countries (such as the UK, USA, etc), the emerging industrial countries (or regions) are still in the rising phase, and their financial system are not yet complete and lack of competitive strength. If they had kept following the Demand-Following theory to gradually develop the financial industry, it was hard to achieve the saltatory development within a short time. Therefore, these countries or regions need to rely on the state or local government's artificially design and policy support, which can accelerate the development of the modernization and internationalization of the financial industry. In the formation and development process of the government-led financial industry cluster, the role of government is active and positive, and the target is quite clear. Through a series of policies to drive the development of the national economy and the financial sector, and beyond development strategies are carried out.

\subsection{Comparison of the Two Formation Mechanisms}

The market-led financial industry cluster and the government-led financial industry cluster base on different theoretical systems, so the differences are significant (see Table 1). Apart from the differences mentioned above, there are some other differences as follows:

In the aspect of functional orientation, for the former, the government generally has no goals beforehand, and the formation of financial industry cluster tend to be accompanied by the economic development; for the latter, the government plays a great role in promoting the formation of the financial industry cluster. In the aspect of policy orientation, the market-led model with the high degrees of freedom and opening on economy, and the government pursues more laissez-faire economic policies; but the government-led model with a high degree of government intervention on economy, and the government always implement relevant policies to support the financial industry cluster. In the aspect of financial role on the economic growth, for the former is the economic development promotes the financial development, and then further promote the economic development; for the latter is the government intends to promote the financial development, and the financial industry positively support the economic development.

For these two models, no one is better than the other. In general, in the early stages of economic development, the government-led model due to the strong policy support, takes less time and quick effectivity; in the advanced stages of economic development, the economic growth leads to further financial development, so the market-led model would be adopted, and government intervention should be as little as possible. In fact, considering from the formation and the long-term development of financial industry cluster, these two models interact and transform with each other and cannot be completely separated. The countries can select an appropriate model according to their actual development phases. Actually they often adopt a combination of the two models, and one of the models is the main path to form the financial industry cluster.

\section{The Basic Elements of the Financial Industry Cluster}

Different from general manufacture industry cluster, financial industry has larger range of customers and more

Table 1. Comparison of two formation mechanisms.

\begin{tabular}{|c|c|c|}
\hline Formation mechanism & Market-led model & Government-led model \\
\hline Theoretical Basis & Demand-Following theory & Supply-Leading theory \\
\hline Generate motivation & Motive power of economic development & Government subjective impetus \\
\hline Generating countries & Developed capitalist countries & Newly industrialized countries \\
\hline Functional orientation & $\begin{array}{l}\text { The Government did not specify in advance } \\
\text { the development objectives, and financial } \\
\text { gather along with economic development } \\
\text { gradually }\end{array}$ & $\begin{array}{l}\text { The Government has specific planning and } \\
\text { positioning, that is to promote economic and } \\
\text { industrial development finance through financial } \\
\text { agglomeration, and expand radiation effects }\end{array}$ \\
\hline Related policy & $\begin{array}{l}\text { A high degree of freedom and opening, and } \\
\text { more laissez-faire policies }\end{array}$ & $\begin{array}{l}\text { Government actively supports and the high level } \\
\text { of intervention }\end{array}$ \\
\hline $\begin{array}{l}\text { The role of the financial industry } \\
\text { to the economy }\end{array}$ & $\begin{array}{l}\text { The financial industry produces passive } \\
\text { reaction on the economy }\end{array}$ & $\begin{array}{l}\text { Financial industry develops actively to support } \\
\text { economic development }\end{array}$ \\
\hline
\end{tabular}


special products, which has important interaction with social economy. Based on the analysis about the formation mechanism of the financial industry cluster, we can see that whatever the model of the financial industry cluster has high requirements for the lever of economic development of region, the existing basis for the financial industry, geographical location, the associated development of supporting industries, the gathering senior financial professionals and so on [12].

\subsection{Strong Economic Foundation}

The economic prosperity and stable development lays an important material foundation for the establishment and growth of the financial industry cluster. The market-led financial industrial cluster is the result of market's long-term development, and it builds on the strong economic strength of the country's central city; even the government-led financial industrial cluster also needs a certain economic scale and comprehensive country masterpiece. After all, the expansion of economic scale and development is a prerequisite for generation of the supply and demand of funds. For example, the development of the financial industry in London depends on its strong economic strength. Before the First World War, Britain was the most advanced and the most powerful capitalist country in the world, so-called "the world factory"; the development of New York's financial industry relied on the rapid rise of the United States after the Second World War, and making it become the most powerful country in the world; Due to the rapid development of Japanese economy in 1980s, Tokyo become the second largest economy in the world, but in 1990s, Japan's economic bubble burst, and it made Tokyo's financial industry lost its global-center status over 10 years. In recent years, Beijing, Shanghai, Shenzhen rank high in the international financial comprehensive competitiveness, and it mainly rely on the sustained, stable and highspeed economy development after the reform and opening up in China. Therefore, a strong economic foundation is the most important condition of the establishment of the financial industrial cluster.

\subsection{The Rapid Development of the Financial Industry}

The places with high degree of financial agglomeration around the world are often the region's financial center, and its requirements for the financial industrial cluster are constantly improving, and accelerating the development of the financial industry is necessary, which embodies in follow aspects:

Firstly, a lot of diversified financial institutions is necessary. Not only the traditional financial institutions, such as banks, insurances, securities, but also the new financial institutions to provide other financial services, such as trust companies, finance leasing companies, fund management companies, finance companies, consumer finance companies, etc. And the sources of financial institutions should be widespread, not only from all over China, but also from multinational financial institutions of other countries around the world.

Secondly, it should have the sound financial market, including the perfect financial market system and a certain scale of the financial market. The perfect system embodies in containing various of financial markets, such as money market, capital market, insurance market, foreign exchange market, gold market, etc. A certain scale of the financial market is as follows: the volume of financial transactions, the attraction of larger funds, the market transaction price can significantly affect other areas of similar financial commodity trading price.

Thirdly, the perfect and efficient financial supervision system is necessary. On the one hand, have a complete financial laws and regulations to ensure the financial institutions and all the financial activities smooth running. On the other hand, the financial regulators need to coordinate with each other to make efficiently operation, and to prevent and resolve the financial risks.

Fourthly, the regions or countries need to have a high degree of financial liberalization and internationalization. It embodies in the less government intervention to the economic development and the capital flows freely. For example, the Wall Street becomes "the financial heart of the world", has the world's largest bond market, benefiting a lot from the rapid development of New York's financial industry and the relatively loose financial environment in the United States; The development of Hong Kong's financial industry is because of its world famous offshore financial center position. The banks, securities, insurances and other financial institutions from other countries gather here, and form a wide range of financial institutions and financial markets. The financial industry has become one of the pillar industries in Hong Kong, and the aggregation degree of the financial institutions is very high, which calculated in accordance with the Hong Kong's area and population.

\subsection{Superior Geographical Location}

The practice has proved that the financial industry has chosen the geographical location when it arising. An ob- 
vious phenomenon is that the world's major financial industry basically locate around the transportation hub and commercial center of the country or region, which with the convenient traffic conditions and the rapid development of commerce and trade to bring enormous financing needs. And the excellent geographical location is the natural advantages to promote the financial industry and produce the formation of financial industry cluster. Excellent location embodies in two aspects: convenient transport location and excellent time zone location. The convenient traffic location tends to bring a lot of trade needs, which stimulates capital flowing, makes collecting and transmitting financial information more timely and effective. And excellent time zone location guarantees that the local financial market becomes an essential part of the world's 24 hours of continuous operation of financial markets [13]. For example, Singapore is located in the Malacca Strait choke while in the Asian time zone, which is good to complement London, New York, Tokyo three major international financial centers of financial markets; Hong Kong is southern gateway of China, the Pearl River and South China Sea throat and the hub of Asia and the world fairway.

\subsection{The Continuous Improvement of Infrastructure}

In addition to superior natural geographical location, the completed infrastructure is also one of the factors to be considered when the financial institutions and the multi-national corporations choose site. The main infrastructure includes transport, communications, building, education and health care and so on. The developed road, rail, air transport can speed up the flow speed of the staff and the goods. The convenient communication facilities and Internet ensure the effective delivery and efficient collection of financial information, and promote the development of financial activities. Especially, modern finance trades are online trading, and the degree of development of the Internet and communication facilities directly affect the aggregation of the financial industry. The commercial building provides enough place for financial institutions and their supporting services office and more choice. A sound health care system provides a convenient solution to their worries. Therefore, improving infrastructure is conducive to the development of the financial sector. For example, London is the world's largest international port and shipping markets, with Europe's largest passenger Heathrow; Hong Kong has world-class financial networks, transportation and communications infrastructure network, and it is regarded as the world's best deep-water port. According to throughput, its container port is the world's busiest container port.

\subsection{Plenty of Highly Qualified Financial Professionals}

The financial industry is a technology-intensive and personnel-intensive industry, where human capital is the core element of financial sector development. The size and quality of the human capital determines whether the financial industry clusters can be sustained and healthy or not. The talents financial institutions need are multifaceted: professional financial knowledge, proficient computer and financial data processing and financial analysis, extensive experience in legal, asset valuation, credit rating, investment advice and other financial support services, foreign language proficiency and so on. Financial professionals gathering not only provides personnel support to gather financial institutions, but also the fundamental guarantee of the financial innovation and financial market boom. For example, London has many world-class universities, Oxford and Cambridge, which provides the world's most advanced financial senior professionals for the financial industry to gather in London; For Beijing, the most advantages of the development of the financial sector is the elite gathering to provide the necessary variety of human capital.

\subsection{Stable Political and Social Environment}

Stable society and Politics is an important factor during the financial industry cluster forming process, because political stability directly affects the country's economic development and stability and the stability of the national currency exchange rate, determines the extent of the country's all industry sectors, thus affects the location choice of the country's financial institutions and investors' confidence to the financial markets. Historical experience shows that development of the financial industry cluster needs a stable political and social environment. Frequent wars, changing leaders and other political instability phenomena in a country or region seriously affect the overall operation of the economy. As a result, the financial gathering also cannot be formed here. After the European sovereign debt crisis, in countries like Greece, Ireland, Spain, Italy, and even the EU's second largest economy, France, there are workers striking. The euro falls sharply, and financial centers in major cities throughout the euro area are significantly affected; Again in 2011 September, originating in the United States, 
spreading to Europe, “Occupy Wall Street” movement, though unable to simply shake Wall Street's role in the world financial sector, but the operation of its financial institutions, especially financial image is greatly affected.

\section{Conclusion}

With the rapid development of China's financial industry, the geographic concentration phenomenon of the domestic financial institutions is surging. At present, there are some typical financial industrial clusters have formed, like Shanghai financial industrial cluster, Beijing financial industrial cluster, and Shenzhen financial industry cluster. According to the formation mechanism, the foundation of Shanghai financial industry is solid, and the financial industry cluster mainly follows the Demand-Following theory, which largely belongs to the market-led model. For Beijing financial industry, the policies play a leading role, and the financial industry cluster follows the Supply-Leading theory, which belongs to the government-led model. The city of Shenzhen adjacent to Hong Kong and the oldest reform and opening city in China, mainly follows the Demand-Following theory. In general, because of the time of Chinese market economy is relatively short; the development of the financial industry cannot be compared to the developed countries and international financial center, such as London, New York and other spontaneous model. Even in the high degree of Shanghai and Shenzhen markets, the government's role is very important in the formation of the financial industry cluster. So, for the construction of industrial clusters of other cities, the paper advocates taking supplied leading path of a government-led mode, basing on the six more fully developed and perfected basic elements, playing government policy support for the development of the financial sector actively, through introducing various preferential policies and providing good financial ecological environment for domestic and foreign financial institutions to gather there.

\section{Acknowledgements}

This research was supported by the project of philosophy and social sciences foundation of Sichuan Province (SC14B065) and the key project of education department of Sichuan province (13SA0135). The work was supported by the Construction Plan of Scientific Research Innovation Team for Colleges and Universities in Sichuan Province (15TD0004).

\section{References}

[1] Lian, J.H., Sun, H.M. and Zhong, H.B. (2005) Financial Enterprise Clusters: Economic Nature, Efficiency Boundary and Competitive Advantage. Financial Research, 6.

[2] Wang, B.F. (2006) Research on the Advantages and Development of Capital Finance Industrial Custers. Beijing Economic Management College, Beijing.

[3] Teng, C.Q. (2006) Financial Enterprise Cluster: The Rise of a New Financial Agglomeration. Shanghai Financial, 5.

[4] Liang, Y. (2006) Review of Financial Industry Cluster. Economic Perspectives, 8.

[5] Liu, H. and Ye, Y.M. (2007) The Financial Agglomeration Effect under Transaction Costs Perspective. Financial Theory and Practice, 12.

[6] Friedmann, J. (1986) The World City Hypothesis, Development and Change. International Journal of Urban and Regional Research, 17, 69-83.

[7] Fan, F.Z., Tang, Y.G. and Qi, X.L. (2004) Empirical Research on Domestic and International Banking Aggregates in Shanghai Motivation. Shanghai University of Finance and Economics, Shanghai.

[8] Hu, J. and Yang, S.L. (2003) The Building of International Financial Center Assessment Index System. Peking University, Beijing.

[9] Patrick, H.T. (1966) Financial Development and Economic Growth in Undeveloped Countries. Economic Development and Cultural Change, 34.

[10] Fujita, M., Krugman, P. and Venables, J. (1999) Spatial Economy: Cities, Regions and International Trade. MIT Press, Cambridge.

[11] Liang, Y. and Luo, X. (2006) Research on the Formation Model Financial Industry Cluster: Global Perspective and the Choice of China. Nanjing University of Finance and Economics, 5.

[12] Yu, L.X. (2012) Study on the Effect of Financial Industry Cluster to Regional Economic Growth. Southwest University of Finance and Economics Doctoral Thesis.

[13] Ni, P.F. (2004) The Construction of International Financial Center: Global Vision, International Standards and World Experiences. Opening Herald, 2. 